\title{
Internet users engage more with phatic posts than with health misinformation on Facebook
}

\author{
Manon Berriche (iD) ${ }^{1} \&$ Sacha Altay (i] ${ }^{2 凶}$
}

\begin{abstract}
Social media like Facebook are harshly criticized for the propagation of health misinformation. Yet, little research has provided in-depth analysis of real-world data to measure the extent to which Internet users engage with it. This article examines 6.5 million interactions generated by 500 posts on an emblematic case of online health misinformation: the Facebook page Santé + Mag, which generates five times more interactions than the combination of the five best-established French media outlets. Based on the literature on cultural evolution, we tested whether the presence of cognitive factors of attraction, that tap into evolved cognitive preferences, such as information related to sexuality, social relations, threat, disgust or negative emotions, could explain the success of Santé + Mag's posts. Drawing from media studies findings, we hypothesized that their popularity could be driven by Internet users' desire to interact with their friends and family by sharing phatic posts (i.e. statements with no practical information fulfilling a social function such as "hello" or "sister, I love you"). We found that phatic posts were the strongest predictor of interactions, followed by posts with a positive emotional valence. While $50 \%$ of the posts were related to social relations, only $28 \%$ consisted of health misinformation. Despite its cognitive appeal, health misinformation was a negative predictor of interactions. Sexual content negatively predicted interactions and other factors of attraction such as disgust, threat or negative emotions did not predict interactions. These results strengthen the idea that Facebook is first and foremost a social network used by people to foster their social relations, not to spread online misinformation. We encourage researchers working on misinformation to conduct finer-grained analysis of online content and to adopt interdisciplinary approach to study the phatic dimension of communication, together with positive content, to better understand the cultural evolution dynamics of social media.
\end{abstract}

\footnotetext{
${ }^{1}$ médialab Sciences Po, Center for Research and Interdisciplinarity, Descartes University, Paris, France. ${ }^{2}$ Institut Jean Nicod, Département d'études cognitives, ENS, EHESS, PSL University, CNRS, Paris, France. ${ }^{凶}$ email: sacha.altay@gmail.com
} 


\section{Introduction}

ince the American presidential election and the Brexit vote of 2016, concerns about the issue of fake news have gained in importance, and social media like Facebook have been harshly criticized for the propagation of misleading content (e.g., Bennet et al., 2016; Silverman, 2016; Tapper, 2016). So far, however, most of the research on the phenomenon has focused on political fake news. By contrast, health and scientific misinformation have received little attention (Wardle and Derakhshan, 2017) while raising important concerns for society (SwireThompson and Lazer, 2019). Still, different types of health-related information disorders have to be distinguished. While disinformation includes false information intentionally designed to cause public harm and spread through coordinated tactics, misinformation encompasses false or inaccurate information not created with malevolent intention (Wardle and Derakhshan, 2017, p. 20; European Commission, 2018; Benkler et al., 2018). In the present article, we remain agnostic about senders' intentions and therefore preferred the broader concept of misinformation to disinformation. More specifically, we will use "health misinformation" to refer to information "that is contrary to the epistemic consensus of the scientific community regarding a phenomenon" (Swire-Thompson and Lazer, 2019, p. 14.2).

A recent systematic literature review revealed that healthrelated misinformation "is highly prevalent on social media and tends to be more popular than accurate information" (Wang et al., 2019, p. 8). Moreover, by shaping people's beliefs, intentions, and behaviors, exposure to inaccurate health statements has the potential to lead to dramatic consequences on public health issues (Tan et al., 2015). For instance, beliefs in antivaccine conspiracy theories could reduce vaccination intentions (Jolley and Douglas, 2014). But empirically very few cases of harm have been associated with health misinformation consumption (Crocco et al., 2002; Pew Research Center, 2015).

In France, this fear about the impact of health misinformation crystallizes around the Facebook page Santé $+\mathrm{Mag}^{1}$, which has been described by several press articles as an emblematic case of health misinformation (Bafoil, 2018; Sénécat, 2018, 2019). In spite of regularly posting health misinformation, including potentially dangerous advice (e.g. "Use frozen lemons to fight diabetes, cancer, obesity and many other diseases"), it attracts a considerable audience: Santé + Mag has more than 8 million Facebook followers, and, with an average of 11 million interactions per month, it generates five times more interactions than the combination of the five best-established French media outlets (Fletcher et al., 2018). Yet, however worrisome these figures may seem, it is not possible to conclude from them that Santé + Mag is popular because it spreads health misinformation. No content analysis has been conducted to capture (1) the extent to which Santé + Mag publishes health misinformation, by contrast with other content, and (2) the extent to which the health misinformation posted on Santé + Mag is particularly successful.

To answer these questions, we conducted in-depth analyses of 500 posts that had generated, in 21 days, a total of $6,483,888$ interactions: comments, shares, or reactions (i.e. "like", "love", "wow", "haha", "sad", or "angry"). On average, each post received 12,968 interactions. In line with previous findings (Fletcher et al., 2018), these figures support the fact that Santé + Mag posts generate impressive numbers of interactions in a short period of time. However, this massive volume of interactions hides important disparities that need to be further analyzed. For instance, while the post that triggered the most interactions generated 207,047 interactions, the one that triggered the least interactions received merely 133 interactions. Our goal was to identify the traits of posts that made them more or less likely to generate interactions.
In order to formulate a series of hypotheses about what factors could make some posts more successful than others on Santé + $\mathrm{Mag}$, we adopted an interdisciplinary approach, drawing on findings coming both from the field of cultural evolution (section "Cultural attraction theory") and media studies (section "Phatic communication and social media"). The former has shown that information content, tapping into evolved cognitive preferences, is a strong determinant of its cultural success (Sperber, 1996; Claidière and Sperber, 2007; Scott-Phillips et al., 2018). The latter has focused on studying the function of information consumption (Katz et al., 1974), and has emphasized how content sharing on social media is driven by Internet users' desire to interact with their relatives (Cardon, 2008; Bastard et al., 2017). By combining these approaches, we explored the extent to which posts' success can be explained by both the cognitive attractiveness of their content and the social function they fulfill.

Cultural attraction theory. Cultural attraction theory, an important theory in the field of cultural evolution, posits that the spread and stabilization of some cultural items (e.g. beliefs, narratives, rumors, etc.) in a population result from psychological or ecological factors of attraction (i.e. properties that facilitate the cognitive mechanisms of information processing, making them more appealing, attention-grabbing and memorable for the human mind; Sperber, 1996; Claidière and Sperber, 2007; ScottPhillips et al., 2018).

Recent research adopting this theoretical background to study digital media and online misinformation has proven fruitful (Acerbi, 2016, 2019, 2020). For example, Acerbi (2019) recently suggested that false information thrives not because it is lowquality information but due to its high psychological attractiveness. Being false per se does not increase the chances of information to become culturally successful, but having properties particularly appealing to the human mind does so (e.g. eliciting threat, disgust or related to social relations, see infra). Since false information is not constrained by reality, it can more easily be designed to recruit cognitive factors of attraction likely to appeal to the human mind and increase interactions (Acerbi, 2019). For example, in the current digital environment, information producers are encouraged to design clickbait-content with catchy titles to spur Internet users to react on them and to generate profit from their clicks.

This led us to formulate the following hypotheses:

$\left(\mathrm{H}_{1}\right)$ Health misinformation is a positive predictor of interactions only if it contains cognitive factors of attraction.

More broadly, cognitive factors of attraction should not only predict the success of health misinformation, but also of other types of content posted by Santé + Mag. In the section below, we formulated a series of predictions for each major cognitive factors of attraction which have been found to increase content transmission.

First, if it is broadly admitted in the literature on cultural evolution that negative information is more easily transmitted than positive information (Heath, 1996; Fessler et al., 2014; Bebbington et al., 2017; Boyer, 2018), even though some research brings these findings into question (Berger and Milkman, 2012; van Leeuwen et al., 2018; Stubbersfield et al., 2017; Altay and Mercier, 2020). For instance, it has been found that positive content is more viral than negative one (Berger and Milkman, 2012) and that morally good content is transmitted with greater fidelity compared to neutral or morally bad content (Stubbersfield et al., 2019). Besides, statistics and surveys on web use indicate that Internet users exchange more compliments on social 
networks than hate speech (Cardon, 2019, p. 178). Despite these contradictory findings, we followed the predictions made by the majority of studies and formulated the hypothesis that:

$\left(\mathrm{H}_{2}\right)$ Negative content generate more interactions than neutral content or positive content.

Second, human attentional resources may be more sensitive to informational cues eliciting threat and danger because the costs of overdetecting them is higher than the one of underdetecting them (Blaine and Boyer, 2018; Boyer, 2018, pp. 78-79; for a general account of these cost asymmetries, see Haselton and Nettle, 2006; Haselton et al., 2015). Furthermore, it seems that this factor of attraction is particularly prevalent in the content of fake news (Vosoughi et al., 2018). For instance, Acerbi (2019) revealed that $28 \%$ of the 260 fake news articles he surveyed contained threatrelated information. Chua and Banerjee (2018) found that people were more prone to trust and to share dread cancer-related rumors rather than wish ones. This leads us to predict that:

$\left(\mathrm{H}_{3}\right)$ Threat-related posts generate more interactions than nonthreatening posts.

Third, content eliciting disgust seem to be particularly culturally successful (Heath et al., 2001; Nichols, 2002; Eriksson and Coultas, 2014): they are better memorized (Stubbersfield et al., 2015), and people are more willing to transmit them (van Leeuwen et al., 2018). Disgust-eliciting content is also more prevalent among fake news (Vosoughi et al., 2018). We thus predicted that:

$\left(\mathrm{H}_{4}\right)$ Disgust-related posts generate more interactions that nondisgusting-related posts.

Fourth, we took mentions of sexual themes into account. If sexrelated information has not been specifically studied in the fields of cultural evolution (Acerbi, 2019), some research has suggested that social information mentioning sexual affairs benefited from an advantage in transmission over other type of social information (Mesoudi et al., 2006). Besides, a meta-analysis showed that sexual appeal in ads has a significant positive effect on ad recognition and recall, though not on attitude towards ads or on purchase intention (Wirtz et al., 2018). Sexually related information is extremely popular among press articles and notably among the most successful fake news. For instance, in 2017, the most shared piece of fake news on Facebook was entitled "Babysitter transported to hospital after inserting a baby in her vagina" (Silverman, 2016). In the same register, in France, the most diffused false news was: "Woman develops IQ of 220 after drinking sperm every day for a year" (Sénécat, 2017). Thus, we predicted that:

$\left(\mathrm{H}_{5}\right)$ Sex-related posts generate more interactions than non sex-related posts.

Fifth, we considered references to social relations. According to the social brain hypothesis (Dunbar, 1998b, 2003), humans are endowed with numerous cognitive systems that have been selected through the course of evolution because they allowed our ancestors to navigate a highly social world. For example, language allows us to share information about our conspecifics, facilitating partner choice and social coordination (Dunbar, 1998a, 2004; Boyer 2001). In support of this theoretical perspective, experimental studies have shown that people recall social stories better than nonsocial ones (Redhead and Dunbar, 2013), and are more willing to transmit social information than nonsocial information (Messoudi et al., 2006; Stubbersfield et al., 2015, 2017). Based on these findings, we predicted that:
$\left(\mathrm{H}_{6}\right)$ Social content should generate more interactions than non social content.

The literature reviewed above focuses on information content. But content is not the only determinant of information transmission. For instance, a recent study showed that the willingness to transmit content with different emotional valence could vary according to the addressee (e.g. a stranger, a friend, or a not very appreciated individual), with participants preferring to transmit emotional content to their friends rather than to other addressees (van Leeuwen et al., 2018), suggesting that people's preferences for certain types of content are modulated by particular social considerations. Other studies in cultural evolution also pointed out that the willingness to transmit threat-related information or pseudoscientific beliefs could be motivated by a desire to look competent (Boyer and Parren, 2015; Mercier et al., 2018).

This fits well with findings from media studies, highlighting that people consume information not only for their content but also for their function (i.e. how they could use it to satisfy specific needs, such as to entertain or to enhance one's social relations).

Phatic communication and social media. In line with a large body of research in media studies looking at the purposes for which media are used (e.g. Katz et al., 1974; Pasquier, 1994, 1995, 2014; Le Grignou, 2003; for a review see Maigret, 2003, 2015), we consider in the section below the function that content shared on Facebook could fulfill and how it can inform the interactions that Santé + Mag generates.

Facebook is mainly used to maintain existing offline relationships (Ellison et al., 2007; 2011), for interpersonal conversation with friends and family, and less to share information from traditional outlets (Bastard et al., 2017). A recent analysis of the Facebook accounts of working-class people also revealed that they shared many posts containing proverbs about family or everyday life that can be perceived as "relational resources to think of collective moral conducts" (Pasquier, 2018, p. 90). In other words, on Facebook, people seem to be driven by bonding strategies (i.e. they seek to strengthen their links with their close relations but not to meet strangers; Cardon, 2008). It has even been suggested that the language used on this social network is flooded with small talk and phatic communication (Manovich, 2001; Miller, 2008). The term "phatic" was first coined by Malinowski (1923, p. 315), to define "language used in free, aimless, social intercourse". In linguistics, the notion of phatic function was established by Roman Jakobson (1960) as one of the six main functions of language in order to qualify statements that do not convey factual information but which are used to engage, maintain, or facilitate social interactions, such as "hello!".

Traditionally, phatic statements might have been only expressed by people in private conversational spaces, but with the emergence of the Web 2.0., media outlets have also begun to use new forms of expression and new registers of enunciation, more relaxed and subjective, to interact with their audience (Cardon, 2010, pp. 73-76). Regarding Santé + Mag, a first exploratory analysis revealed that it contained many posts with short sentences such as "Hi my sister, I just want you to know that I love you more than anything in the world" or "A kisses for each of you good weekend to all", making them look more like greeting cards than news (see Fig. 1). Based on these findings from media studies, we predicted that how a post could be usedi.e. its phatic function-should also be a determinant of a post success. Hence our last hypothesis:

$\left(\mathrm{H}_{7}\right)$ Phatic posts generate more interactions than nonphatic posts. 


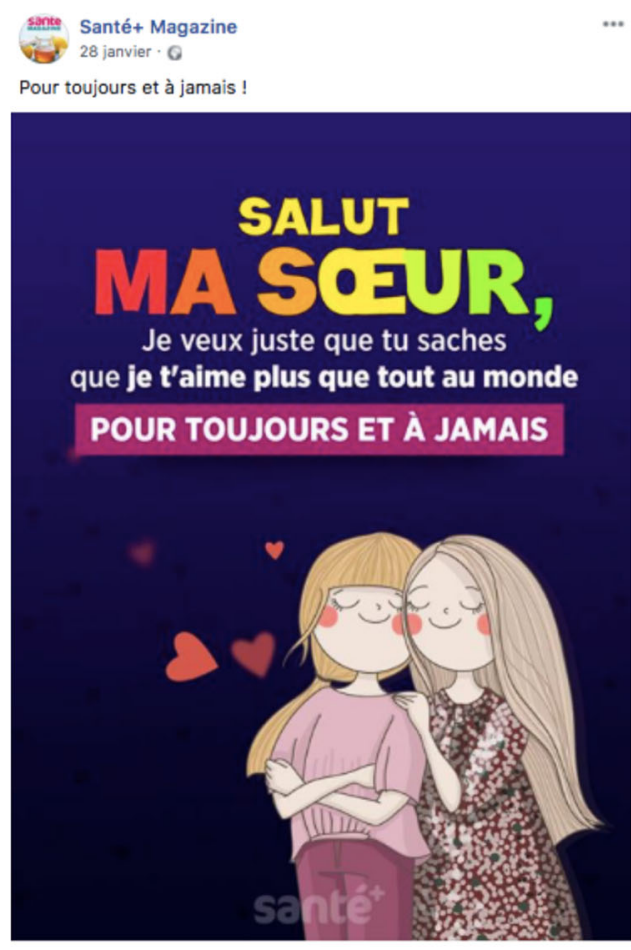

$00 \mathrm{~A} 12 \mathrm{~K}$

$7,8 \mathrm{~K}$ commentaires $20 \mathrm{~K}$ partages
Santé+ Magazine
Bon week-end à tous!

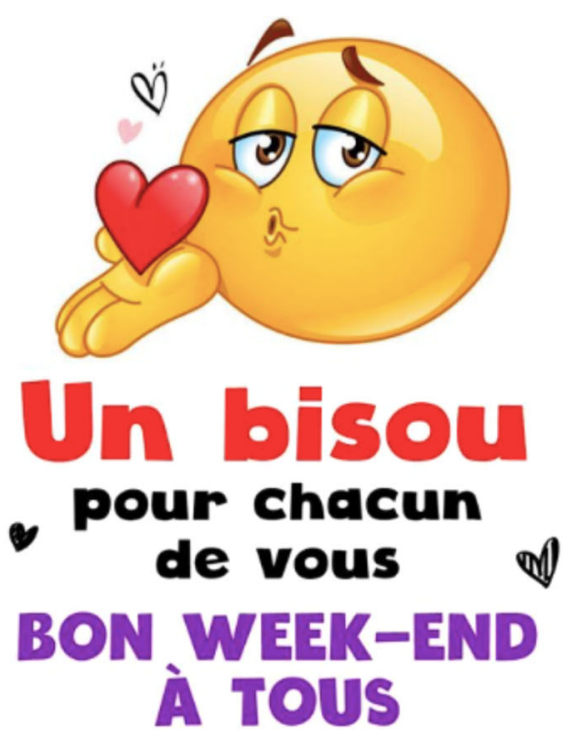

santét

Fig. 1 Examples of phatic posts published by Santé + Mag. On the left: "Hi my sister, I just want you to know that I love you more than anything in the world". On the right: "A kiss for each of you, good weekend to all".

\section{Methods}

Data collection. Thanks to an access to the CrowdTangle API, granted by the Social Science Research Council (SSRC), we collected 500 posts from the Facebook page Santé + Mag, as well as their 2,673,972 reactions, 183,730 comments and 3,626,186 shares (CrowdTangle Team, 2019). These volumes represent all the posts published by Santé + Mag, and all the interactions they generated, over a period of 21 days from January 10 to January 31, 2019. Our access to the Facebook tool CrowdTangle enabled us to observe that over a year-from September 1, 2018 to August 31, 2019-Santé + Mag published on average 709 posts per month, containing $66.2 \%$ of articles, $27.9 \%$ of photos, $5.7 \%$ of videos and $0.2 \%$ of native videos. With $66.6 \%$ of articles, $24.0 \%$ of photos, and $9.4 \%$ of videos, the sample we collected contains similar proportions-suggesting that it is a representative sample of the Facebook page's activity.

To measure the total interactions generated by each post, we aggregated their numbers of reactions, comments and shares. Overall, we obtained a total of $6,483,888$ interactions. We manually transcribed the texts present on visual content and on videos. This approach allowed us to rely on real-world social media data, and on metrics which are more accurate than self-report survey to measure the true success of online health misinformation and to capture people's actual interest for different kinds of content (Houidi et al., 2019). Studies relying on real-life social media data are drastically lacking to understand (i) the spread and impact of health-related information (Verelst et al., 2016; Swire-Thompson and Lazer, 2019) and (ii) "the way audiences access, share and appropriate information" on conversational spaces of communication such as Facebook (Cardon et al., 2019, p. 3). The urgent need to conduct finer-grained analysis of the content shared by lay people on social media has been stressed in the literature, e.g. "because social media platforms have been implicated as a key vector for the transmission of fake news, it is critical to study what people saw and shared directly on social media" (Grinberg et al., 2019, p. 1).
Coding. Each post was manually coded by the first author of the article (see Table 1 of the supplementary material for a synthesis of all our categories).

The first step to code our sample was to evaluate how many posts could be classified as health misinformation. We did so by verifying the validity of each health-related statement by conducting research on the web; by checking if their content had been debunked by a fact-checking website; and by assessing the reliability of each scientific source mentioned. Then, to better gauge the potential noxiousness of Santé + Mag' posts, we also evaluated whether each post classified as health misinformation could be potentially harmful for its reader. As a result, we distinguished two categories of health misinformation. (1) On the one hand, harmful health misinformation that delivered unfounded medical recommendations (e.g. " 5 plants to help you sleep better", "The recipe for ginger tea that cleanses the liver and reduces joint pain"), used scientific authority as a misleading tactic (e.g. "According to a study, men with a big belly are the best lovers"), or that conveyed a noxious false claim related to serious disease (e.g."Chocolate is a natural medicine that lowers blood pressure, prevents cancer, strengthens the brain and much more"), and that could, for all these reasons, wrongly influence people's behavior-if they were to be taken at face value. (2) On the other hand, not harmful misinformation containing staments that were not likely to cause harm such as "People who sings live longer".

All the posts that were not considered as health misinformation were classified as "non health misinformation". In this category the posts were not related to health and were very similar to what can be found in "gossip" magazine, featuring news items (e.g. "Woman organizes photo shoot to celebrate her divorce and sets fire to her own wedding dress"); advices for love and sexuality (e.g. "8 easy things to do to reach orgasm now!"); recipes (e.g. "Here is Granny's yogurt cake, sugar free and gluten free, which makes food lovers crazy") and pictures with phatic 
statement (e.g. "Hello I offer you a good hot coffee and a big kiss. Have a good day").

A second step to better understand the types of content published by Santé + Mag and the reasons of their success was to assess their emotional valence and to track for the presence of the different cognitive factors of attraction mentioned in our introduction (see section "Cultural attraction theory") within each content of our sample: (1) negative emotion; (2) threat (e.g. "Molds disease is spreade everywhere: here are 11 signs that you have it"); (3) disgust (e.g. "Here is the best natural laxative to eliminate all stools stuck in your intestines"); (4) sexuality (e.g. "7 things women want in bed"); (5) social relations (e.g. "She anwsers her husband who cheats on her with her sister").

As a first analysis of our sample revealed the important prevalence of social information among the posts of Santé + Mag, we decided to increase the level of granularity of this category by creating different subcategories in order to identify more precisely which type of social content are more prevalent on Santé + Mag. We thus coded for the presence of different topics, depending on the specific social relations mentioned on each post: (1) family; (2) love; (3) friends; as well as relations with other members of the (4) society or with (5) antisocial people (e.g. free riders, hypocrite, liars), or depending on its emphasize on a specific event of life (6) pregnancy; (7) mourning; (8) infidelity.

Lastly, we assessed the social function of each posts to determine whether they contained an information (i.e. nonphatic posts), or consisted only in stating sentences such as courtesy, greeting, etc. (i.e. phatic post).

To sum up, each post was first classified as (1) health misinformation or not and (2) potentially harmful or not. Then, each post was coded according to (3) its emotional valence, (4) the cognitive factors of attractions it contained and (5) the specific social topics it was about. Lastly, each post was categorized as phatic or not (6). Since each post could have up to two cognitive factors of attraction and could be about up to three social topics, it could have overall up to nine categories.

To ensure the validity of the coding, the second author of the article, as well as three independent coders blind to our hypotheses, coded 50 randomly selected posts each. The coders

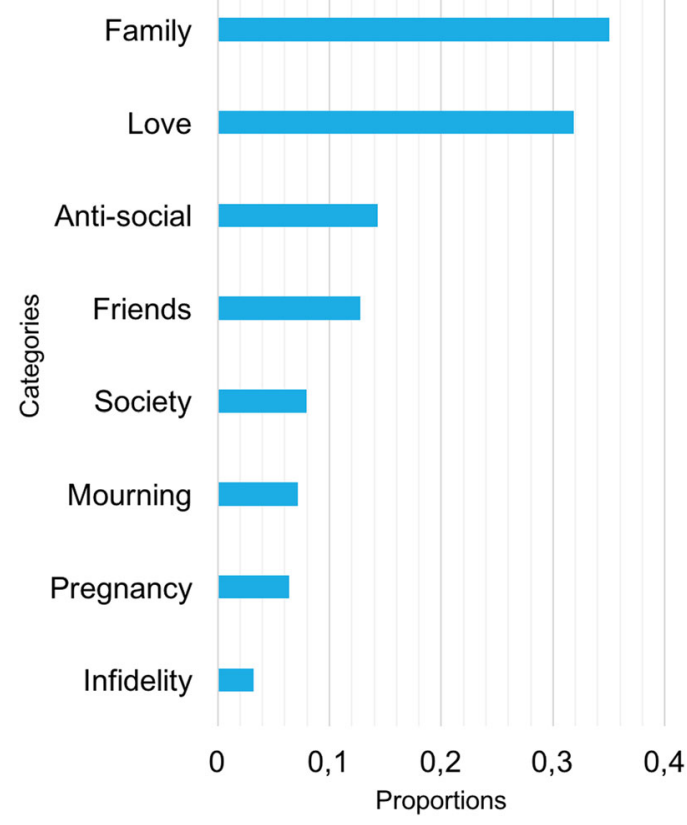

Fig. 2 Topics of social information. Proportions of social information in wich each of the specific sub-category was coded. had to classify each post according to all our categories (i.e. emotional valence, phatic or not, etc., see Supplementary Table 1 for a summary). To measure the inter-rater reliability we calculated Cohen's Kappa coefficients. Agreement scores between the coders and the first author ranged from 85.55 to $90.91 \%$, and the strength of agreement was considered to be "substantial" for coders 2 and 4, and "almost perfect" for coders 1 and 3 (details can be found in Table 2 of the supplementary material).

\section{Results}

What types of content are published by Santé + Mag? $28 \%$ of the posts can be considered as health misinformation. Out of 500 posts analyzed, 28\% (140/500) fit in the category health misinformation, and $21 \%(105 / 500)$ were assessed as potentially harmful. While these proportions are not negligible, they suggest that Santé + Mag publishes a larger proportion of other types of content than health misinformation to attract its huge audience.

More than $50 \%$ of the posts are related to social relations. Looking at the prevalence of cognitive factors of attraction in our sample, we found that $50.4 \%$ of Santé + Mag posts were related to social interactions, $27.8 \%$ to threat, $14.0 \%$ to sexuality, and $2.6 \%$ to disgust. These results show that, on the whole, Santé + Mag publishes a high volume of posts containing cognitive factors of attraction (82.0\%) which could be attention-grabbing for Internet users.

Social information is mainly related to family and affective relations. Within social information, we distinguished between eight subcategories depending on the specific social relations mentioned on each post (e.g. family, romantic or friendly relationships, as well as relations with other members of the society or with antisocial people-free riders, hypocrite, liars) or on a specific life event (e.g. pregnancy, infidelity, mourning). Content related to strong and affective relationships such as family (34.9\%) and love (31.8\%) were the most prevalent (see Fig. 2). This confirms that Santé + Mag Facebook posts are very similar to the types of content that can be found in gossip magazines.

How does the type of content affect interactions?. First, we logtransformed our dependent variable to have a normal distribution of the residuals (Shapiro-Wilk normality test: $W=0.99$, $p=0.28)$. Next, we conducted statistical analyses to measure what best predicted interactions. All statistical analyses in this paper were conducted in R (v.3.6.0, R Core Team, 2017), using R Studio (v.1.1.419, RStudio Team, 2015).

Despite its cognitive appeal, health misinformation negatively predicts interactions. To test $\mathrm{H}_{1}$, we conducted a linear regression with health misinformation containing factors of attraction as only predictor. The model explained $0.03 \%$ of the variance in interactions (adjusted $R^{2}=0.03, \mathrm{~F}(1,498)=15.24, p<0.001$ ) and health misinformation containing factors of attraction was a negative predictor of interactions $(\beta=-0.53, \mathrm{t}(498)=-3.90, p<0.001)$.

Then, we measured the proportion of cognitive factors of attraction present among health misinformation and found that $79.3 \%$ of health misinformation contained at least one cognitive factor of attraction. While health misinformation did not contain significantly more factors of attraction than nonhealth misinformation $\left(\chi^{2}(1, N=500)=0.73, p=0.39, \varphi=0.04\right)$, it was more likely to elicit threat $\left(\chi^{2}(1, N=500)=110.1, p<0.001, \varphi=0.50\right)$, disgust $\left(\chi^{2}(1, N=500)=18.44, p<0.001, \varphi=0.19\right)$ and negative emotions $\left(\chi^{2}(1, N=500)=34.01, p<0.001, \varphi=0.26\right)$, but less likely to be related to social relations $\left(\chi^{2}(1, N=500)=127.94\right.$, 


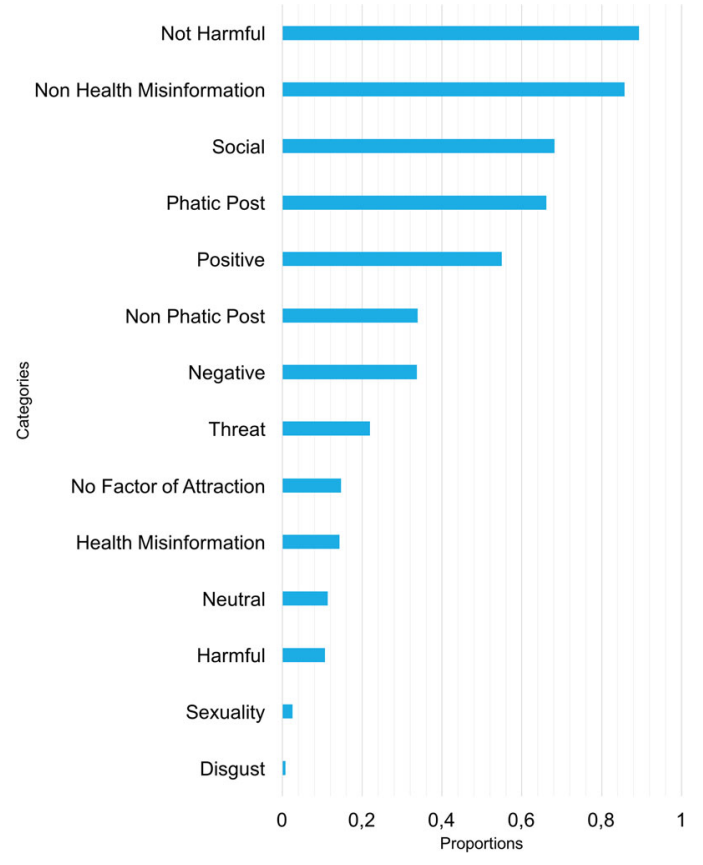

Fig. 3 Posts' success depending on the categories they belong to. Proportion of interactions generated by each category that was coded.

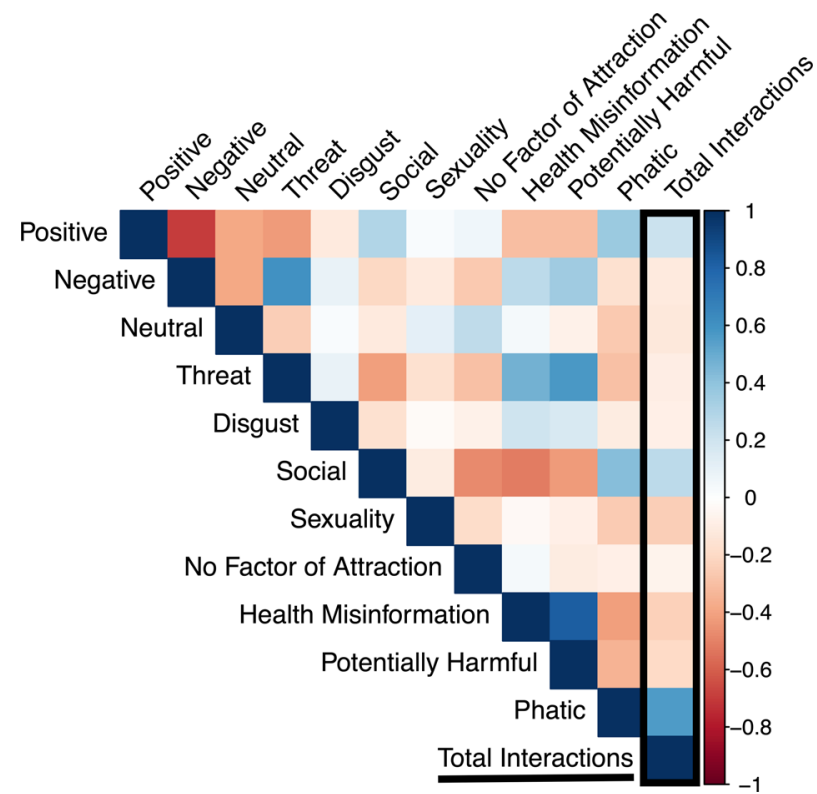

Fig. 4 Correlation matrix for each of the coded variables and the total of interactions. The color of each case indicates the strenght of the correlation between the variables. The more dark blue the box is the more it indicates a strong correlation. The more dark red the box is, the more it indicates an absence of correlation. On the rightmost column, it can be seen for instance that the total of interactions is positively correlated with positive, social and phatic posts but not with the other coded variables.

$p<0.001, \varphi=0.51)$ than non health misinformation. There were no significant differences for the presence of sex-related information and the absence of cognitive factors of attraction.

These results do not support $\mathrm{H}_{1}$ : even if health misinformation published by Santé + Mag was largely appealing, by containing an important proportion of cognitive factors of attraction, particularly likely to elicit threat, disgust and negative emotions, it was a negative predictor of interactions.

To sharpen our analysis, we also tested whether health misinformation containing cognitive factors of attraction was more successful than health misinformation without factors of attraction by conducting a linear regression with the presence of cognitive factors of attraction as a predictor of interactions, among health misinformation. The presence of cognitive factors of attraction was not a significant predictor of interactions $(\beta=0.17, \mathrm{t}(138)=0.93, p=0.35)$. To test whether the number of cognitive factors of attraction was a predictor of interactions among health misinformation, we then conducted a linear regression with the number of cognitive factors of attraction as a predictor of interactions. The number of cognitive factors of attraction was a negative predictor of interactions $(\beta=-0.28, \mathrm{t}$ $(138)=-2.09 p=0.04)$. Finally, we also conducted a linear regression with health misinformation as only predictor to test whether health misinformation had an effect on interaction. The model explained only $3.1 \%$ of the variance in interactions (adjusted $\left.R^{2}=0.03, \mathrm{~F}(1,498)=17.32, p<0.0001\right)$ and health misinformation was a negative predictor of interactions $(\beta=$ $-0.52, \mathrm{t}(498)=-4.16, p<0.001)$.

To sum up, these different findings show that posts classified as health misinformation were not successful on Santé + Mag, and that among this category there was no significant difference for posts containing cognitive factors of attraction and for those without cognitive factors of attraction. In fact, only $14.3 \%$ of the total of interactions came from health misinformation, and this proportion can even be lowered to $10.7 \%$ if we only consider health misinformation that could be potentially harmful. Conversely, most interactions came from information that were not health misinformation (85.8\%) and unlikely to cause harm to their reader (89.3\%) (see Fig. 3).

Health misinformation may be commented for fun or social purposes. In an exploratory analysis of 4737 comments generated by the five most commented posts of our sample classified as potentially harmful health misinformation, we found that only $3 \%$ of the comments reflected an approval of the content, that $12 \%$ express a criticism, and that most comments (48\%) were jokes or had a content likely to fulfill social purposes (e.g. to share a moment of complicity with a friend).

The most commented post ("7 reasons to pass wind more often, it is good for your health") received 1427 comments. A large majority of them (74\%) were jokes or expression revealing that the post was found funny. The users also often tagged one of their Facebook contacts in comments (64\%).

The second most commented post ("According to a study, men with a big belly are the best lovers") received 1363 comments. $26 \%$ of the comments reflected a personal opinion on lover preferences (with a belly or thin), 27\% were jokes, and $27 \%$ mentioned other contacts to ask for their point of view on the topic or to joke with them. $17 \%$ commented it to criticize its lack of reliability.

The third most commented post ("Cannabis causes desire to make love and could even increase pleasure") received 1358 comments. $27 \%$ of the comments criticized the scientific validity of the statement or the lack of credibility of the source. Besides, $25 \%$ of comments on this post contained jokes and $24 \%$ tagged another Facebook contact.

The fourth most commented post ("According to psychologists, friends who are the hardest with you are those who want the most what is good for you") received 1305 comments. A vast majority of them (84\%) tagged a friend and took advantage of the post to talk about their friendship. 
The fifth most commented post ("Chocolate is a natural medicine that lowers blood pressure, prevents cancer, strengthens the brain and much more") received 707 comments. Again, an important majority of the comments (45\%) were made to discuss with other Facebook contacts, mainly to express one's favorite chocolate flavor or habits of chocolate consumption (33\%). By contrast, very few comments were made either to approve the post $(5 \%)$ or either to criticize it $(5 \%)$.

These observations suggest that interactions generated by health misinformation are not necessarily a sign of Internet users' gullibility and that they are not passive receivers of information, taking information content at first value.

Interactions are mainly explained by phatic posts and positive content. To test $\mathrm{H}_{2-7}$ we conducted a multiple regression with all the categories coded (including health misinformation) as predictors of interactions. All the $p$ values reported below have been corrected for multiple comparisons using the Holm-Bonferroni method.

The results of the regression indicated that the model with the ten predictors explained $52.8 \%$ of the variance in interactions (adjusted $\left.R^{2}=.53, \mathrm{~F}(10,489)=56.9, p<0.001\right)$.

The category phatic post was the strongest predictor of interactions $(\beta=1.46, \mathrm{t}(489)=13.59, p<0.001)$, followed by post of positive valence (compared to neutral posts: $\beta=0.40, \mathrm{t}$ $(489)=3.28, p=0.009$; compared to negative posts: $\beta=0.48$, $\mathrm{t}$ $(489)=3.83, p=0.03)$. Phatic posts and posts with a positive emotional valence catalyzed each $66.09 \%$ and $55 \%$ of the total number of interactions, respectively. On the other hand, sexual content negatively predicted interactions $(\beta=-1.14, \mathrm{t}(489)=$ $-7.69, p<0.001)$. We found no significant effect of social information $(\beta=0.14, \mathrm{t}(489)=0.96, p=1)$, threat-related information $(\beta=-0.12, \mathrm{t}(489)=-0.80, p=1)$, disgust-related information $(\beta=-0.54, \mathrm{t}(489)=-2.08, p=0.30)$, negative posts (compared to neutral posts: $\beta=-0.09, \mathrm{t}(489)=-0.68, p=1$ ), health misinformation $(\beta=0.32, \mathrm{t}(489)=1.94, p=0.37)$, information potentially harmful $(\beta=0.06, \mathrm{t}(488)=0.31, p=1)$, and posts that did not contain one of the specific factor of attraction we looked for $(\beta=-0.13, \mathrm{t}(489)=-0.73, p=1)$.

As a result, these findings support $\mathrm{H}_{7}$ but led us to reject $\mathrm{H}_{2-6}$ since phatic posts had a positive effect on interactions, but the presence of cognitive factors of attraction had no significant effect.

The correlation matrix below offers a summary of the strength of the correlation coefficients between our coded variables and the total volume of interactions (see notably the column "Total Interactions" in Fig. 4).

\section{Discussion}

While previous research (Fletcher et al., 2018) and media articles (Bafoil, 2018; Sénécat, 2018, 2019) highlighted that Santé + Mag Facebook page could be an important medium for the propagation of health misinformation, our results suggest that Internet users do not engage that much with its health misinformation posts and are rather attracted by other types of content.

First, we found that health misinformation did not constitute the majority of the posts diffused by Santé + Mag, since it represented $28 \%$ of its publishing activity, and despite its cognitive appeal, it negatively predicted interactions, being responsible for less than $15 \%$ of the total volume of interactions. These results fit well with a large body of studies highlighting that false information is consumed and shared by a very small minority of people (Nelson and Taneja, 2018; Guess et al., 2019; Allen et al., 2020; Grinberg et al., 2019) and that the negative impact of online misinformation is probably overblown (Allcott and Gentzkow,
2017; Benkler et al., 2018; Pennycook et al., 2019; Altay et al., 2019; Acerbi, 2020).

Second, positive content generated more interactions than negative content, and negative content was not more successful than emotionally neutral content. In line with some previous studies (Berger and Milkman, 2012; van Leeuwen et al., 2018; Stubbersfield et al., 2019; Altay and Mercier, 2020), these results mitigate the widespread success attributed to negative content in the field of cultural evolution.

Third, interactions were poorly explained by the presence of identified cognitive factors of attraction: contrary to our predictions, sex-related information was a negative predictor of interactions, and threat, disgust, and social information did not predict interactions.

Finally, the category phatic post was the strongest predictor of interactions, suggesting that on Santé + Mag the social function of a post was a better predictor of its success than its content.

On the whole, this study emphasizes the importance of conducting finer-grained studies on the issue of health misinformation to measure precisely the importance of the phenomenon on social media. Our results show that huge volume of interactions on social media can hide important disparities and that conducting in-depth content analyses is essential to determine what causes these interactions. Researchers working on misinformation should not stop at the interaction rates generated by posts on social media, even when it concerns interactions on content identified as misinformation. As our analysis of the five most commented health misinformation posts showed, interaction with misinformation does not necessarily reflect internet users' passive approbation.

More broadly, our study suggests that adopting an interdisciplinary approach and relying on real-world social media data can help to have a better grasp of the cultural dynamics happening on social media. The literature in cultural evolution might have paid too much attention to threat, disgust and negative emotions, at the expense of positive emotions and the context of information transmission-but recent research have started filling this gap (for the context of information transmission, see van Leeuwen et al., 2018; Boyer and Parren, 2015; Mercier et al., 2018; for positive emotions, see Berger and Milkman, 2012; van Leeuwen et al., 2018; Stubbersfield et al., 2019; Altay and Mercier, 2020). It could also be relevant to pay more attention to the diversity of contexts of communication offered by social media. For instance, the "public-private" character of information shared on Facebook (Cardon, 2008) may explain why sex-related information was not very successful on Santé + Mag, as Internet users could be inhibited to share such information on their public profile but more prone to do so on private conversations with one of their close contact.

Although we focused on one French-speaking Facebook page, other English-speaking Facebook pages publishing health misinformation seem to share the same properties. For instance, the Facebook page Bright Side ${ }^{2}$, that accumulates more than 42 million followers also publish very successful phatic posts with positive messages. An exploratory analysis of the 197 posts published in a week revealed that if only $5.6 \%$ of them could be considered as phatic posts $(35 / 197)$, they were responsible for $41 \%$ of the 1.17 million interactions! This echoes other studies showing that posts containing proverbs on daily life or honoring family ties are massively shared by people on Facebook (Pasquier, 2018, pp. 85-93 and pp. 145-146). Overall, our results strengthen the idea that Facebook is first and foremost a social network used by people to foster their social relations, not to spread online misinformation. 


\section{Data availability}

The dataset analyzed during the present study is available in an Open Science Framework repository: https://mfr.osf.io/render? url=https://osf.io/8bz6n/?direct\%26mode $=$ render\%

26action $=$ download $\% 26$ mode $=$ render. It includes the list of URLs of the 500 posts we examined, our coding and the number of interactions they generated. We can't share however the messages published by Santé + Mag on Facebook with each of its post, neither the text we manually transcribed from visual content and from videos because these content are protected by copyrights. The dataset of our exploratory analysis of the 4737 comments from the five most commented health misinformation is not publicly available because it falls under a certain number of restrictions for sharing.

Received: 5 December 2019; Accepted: 30 March 2020;

Published online: 28 April 2020

\section{Notes}

1 Santé + Mag Facebook page can be consulted at the following link: https://www. facebook.com/santeplusmag/.

2 Bright Side Facebook page can be consulted at the following link: https://www. facebook.com/brightside/.

\section{References}

Acerbi A (2016) A cultural evolution approach to digital media. Front Hum Neurosci 10:636. https://doi.org/10.3389/fnhum.2016.00636

Acerbi A (2019) Cognitive attraction and online misinformation. Palgrave Commun 5(1):1-7. https://doi.org/10.1057/s41599-019-0224-y

Acerbi A (2020) Cultural evolution in the digital age. Oxford University Press, New York, NY

Allcott H, Gentzkow M (2017) Social media and fake news in the 2016 election. J Econ Perspect 31(2):211-236. https://doi.org/10.1257/jep.31.2.211

Allen J, Howland B, Mobius, M, Rothschild, D, Watts, DJ (2020) Evaluating the fake news problem at the scale of the information ecosystem. Sc. Adv, 6(14): eaay3539

Altay S, Mercier H (2020) Framing messages for vaccination supporters. J Exp Psychol App. https://doi.org/10.1037/xap0000271

Altay S, Hacquin AS, Mercier H (2019) Why do so few people share fake news? It hurts their reputation. https://psyarxiv.com/82r6q/

Bafoil P (2018) Fausses rumeurs et prescriptions dangereuses sur "Santé Plus Mag", l'une des pages les plus populaires de Facebook. Les Inrockuptibles. https:// www.lesinrocks.com/2018/01/17/medias/actualite/fausses-rumeurs-etprescriptions-dangereuses-sur-sante-plus-mag-lune-des-pages-les-pluspopulaires-de-facebook/

Bastard I, Cardon D, Charbey R, Prieur C, Cointet JP (2017) Facebook, pour quoi faire? Configurations d'activités et structures relationnelles. Sociologie 8 (1):57-82. https://doi.org/10.3917/res.154.0091

Bebbington K, MacLeod C, Ellison TM, Fay N (2017) The sky is falling: evidence of a negativity bias in the social transmission of information. Evol Hum Behav 38(1):92-101. https://doi.org/10.1016/j.evolhumbehav.2016.07.004

Benkler Y, Faris R, Roberts H (2018) Network propaganda: manipulation, disinformation, and radicalization in American politics. Oxford University Press, New York, NY

Blaine T, Boyer P (2018) Origins of sinister rumors: a preference for threat-related material in the supply and demand of information. Evol Hum Behav 39 (1):67-75. https://doi.org/10.1016/j.evolhumbehav.2017.10.001

Berger J, Milkman KL (2012) What makes online content viral? J Mark Res 49 (2):192-205. https://doi.org/10.1509/jmr.10.0353

Boyer P (2018) Minds make societies: how cognition explains the world humans create. Yale University Press

Boyer P, Parren N (2015) Threat-related information suggests competence: a possible factor in the spread of rumors. PLoS ONE 10(6):e0128421. https:// doi.org/10.1371/journal.pone.0128421

Boyer P (2001) Et l'homme créa les dieux. Gallimard, Paris

Cardon D (2019) Culture numérique. Presses de Sciences Po, Paris

Cardon D, Cointet JP, Ooghe B, Plique G (2019) Unfolding the multi-layered structure of the French mediascape. https://spire.sciencespo.fr/hdl:/2441/ 52avseho8m9ribmeot0eogd0iu/resources/wplmedialab-unfolding-the-multilayered-structure-of-french-media-landscape-vf-2.pdf
Cardon D (2010) La démocratie Internet. Promesses et limites. Éditions du Seuil et la République des Idées, Paris

Cardon D (2008) Le design de la visibilité. Réseaux 6:93-137

Chua AY, Banerjee S (2018) Intentions to trust and share online health rumors: An experiment with medical professionals. Comput Hum Behav 87:1-9. https:// doi.org/10.1016/j.chb.2018.05.021

Claidière N, Sperber D (2007) The role of attraction in cultural evolution. J Cog Cult 7(1-2):1-2. https://doi.org/10.1163/156853707X171829

Crocco AG, Villasis-Keever MJ, adad AR (2002) Analysis of cases of harm associated with use of health information on the Internet. JAMA 287 (21):2869-2871

CrowdTangle Team (2019) CrowdTangle. Facebook, Menlo Park, California. https://apps.crowdtangle.com/mdialab/lists/1261682

Dunbar R (1998a) Grooming, gossip, and the evolution of language. Harvard University Press, Cambridge

Dunbar R (1998b) The social brain hypothesis. Evol Anthropol 6:178-190. https:// doi.org/10.1002/(SICI)1520-6505(1998)6:5<178::AID-EVAN5>3.0.CO;2-8

Dunbar R (2003) The social brain: mind, language, and society in evolutionary perspective. Annu Rev Anthropol 32:163-181. https://doi.org/10.1146/ annurev.anthro.32.061002.093158

Dunbar R (2004) Gossip in evolutionary perspective. Rev Gen Psychol 8 (2):100-110. https://doi.org/10.1037/1089-2680.8.2.100

Ellison NB, Steinfield C, Lampe C (2007) The benefits of Facebook "friends:" social capital and college students' use of online social network sites. J Comput Mediat Commun 12:1143-1168. https://doi.org/10.1111/j.1083-6101.2007.00367.x

Ellison NB, Steinfield C, Lampe C (2011) Connection strategies: social capital implications of Facebook-enabled communication practices. N Media Soc 13 (6):873-892. https://doi.org/10.1177/1461444810385389

European Commission (2018) A multi-dimensional approach to disinformation. Report of the independent High Level Group on fake news and online disinformation

Eriksson K, Coultas JC (2014) Corpses, maggots, poodles and rats: emotional selection operating in three phases of cultural transmission of urban legends. J Cog Cult 14(1-2):1-26. https://doi.org/10.1163/15685373-12342107

Fletcher R, Cornia A, Graves L, Nielsen RK (2018) Measuring the reach of "fake news" and online disinformation in Europe. Factsheets Reuters Institute, p 1 -10 . https://www.press.is/static/files/frettamyndir/reuterfake.pdf

Fessler DM, Pisor AC, Navarrete CD (2014) Negatively-biased credulity and the cultural evolution of beliefs. PLoS ONE 9(4):e95167. https://doi.org/10.1371/ journal.pone.0095167

Grinberg N, Joseph K, Friedland L, Swire-Thompson B, Lazer D (2019) Fake news on Twitter during the 2016 US presidential election. Science 363 (6425):374-378. https://doi.org/10.1126/science.aau2706

Guess A, Nagler J, Tucker J (2019) Less than you think: prevalence and predictors of fake news dissemination on Facebook. Sci Adv 5(1):eaau4586. https://doi org/10.1126/sciadv.aau4586

Haselton MG, Nettle D, Murray DR (2015) The evolution of cognitive bias. In: Buss DM (ed.) The handbook of evolutionary psychology. Wiley, New York, 724-746

Haselton MG, Nettle D (2006) The paranoid optimist: An integrative evolutionary model of cognitive biases. Pers Soc Psychol Rev 10(1):47-66. https://doi.org/ 10.1207/s15327957pspr1001_3

Heath C, Bell C, Sternberg E (2001) Emotional selection in memes: the case of urban legends. J Pers Soc Psychol 81(6):1028. https://doi.org/10.1037/00223514.81.6.1028

Heath C (1996) Do people prefer to pass along good or bad news? Valence and relevance of news as predictors of transmission propensity. Organ Behav Hum Decis Process 68(2): 79-94. https://doi.org/10.1006/obhd.1996.0091

Houidi ZB, Scavo G, Traverso S, Teixeira R, Mellia M, Ganguly S (2019) The News We Like Are Not the News We Visit: News Categories Popularity in Usage Data. Proceedings of the International AAAI Conference on Web and Social Media 13 (1): 91-102. https://www.aaai.org/ojs/index.php/ICWSM/article/view/3212

Jakobson R (1960) Concluding statement: linguistics and poetics. In: Sebeok T (ed.) Style in language. MIT Press, Cambridge

Jolley D, Douglas KM (2014) The effects of anti-vaccine conspiracy theories on vaccination intentions. PLoS ONE 9(2):e89177. https://doi.org/10.1371/ journal.pone.0089177

Katz E, Blumler JG, Gurevitch M (1974) Utilization of mass communication by the individual. In: Blumler JG, Katz E (eds) The uses of mass communications: current perspectives on gratifications research. Sage Publications, Beverly Hills

Le Grignou B (2003) Du côté du public: usages et réceptions de la télévision. Economica, Paris

Maigret E (2015) Sociologie de la communication et des médias. Armand Colin, Paris

Maigret E (2003) Communication et médias. La documentation française, Paris

Malinowski B (1923) The problem of meaning in primitive languages. In: Ogden, K. Richards IA (eds) The Meaning of Meaning. London: Routledge and Kegan Paul 451-510 
Manovich L (2001) The language of new media. MIT Press, Cambridge, MA and London

Mercier H, Majima Y, Miton H (2018) Willingness to transmit and the spread of pseudoscientific beliefs. Appl Cogn Psychol 32(4):499-505. https://doi.org/ 10.1002/acp. 3413

Mesoudi A, Whiten A, Dunbar R (2006) A bias for social information in human cultural transmission. Br J Psychol 97(3):405-423. https://doi.org/10.1348/ $000712605 \times 85871$

Miller V (2008) New media networking and phatic culture. Convergence 14 (4):387-400. https://doi.org/10.1177/1354856508094659

Nelson JL, Taneja H (2018) The small, disloyal fake news audience: the role of audience availability in fake news consumption. N Media Soc 20 (10):3720-3737. https://doi.org/10.1177/1461444818758715

Benett J, et al. (2016) Facebook and the digital virus called fake news. New York Times. https://www.nytimes.com/2016/11/20/opinion/sunday/facebook-andthe-digital-vi-rus-called-fake-news.html

Nichols S (2002) On the genealogy of norms: a case for the role of emotion in cultural evolution. Philos Sci 69(2):234-255. https://doi.org/10.1086/341051

Pasquier D (2018) L'Internet des familles modestes. Enquête dans la France rurale. Presse des Mines, Paris

Pasquier D (2014) La culture des sentiments: l'expérience télévisuelle des adolescents. Editions de la Maison des Sciences de l'Homme.

Pasquier D (1995) Chère Hélène». Les usages sociaux des séries collège. Réseaux. Commun-Technologie-Société 13(70):9-39

Pasquier D (1994) Vingt ans de recherches sur la télévision: une sociologie post lazarsfeldienne? Sociologie du Trav 36(36):63-84

Pennycook G, Epstein Z, Mosleh M, Arechar, AA, Eckles D, Rand D (2019) Understanding and reducing the spread of misinformation online. https:// psyarxiv.com/3n9u8/

Pew Research Center (2015, January 22) Most view the CDC favorable; VA's images lips. Pew Research Center. U.S. Politics \& Policy. https://www.peoplepress.org/2015/01/22/most-view-the-cdc-favorably-vas-image-slips/

Redhead G, Dunbar RIM (2013) The functions of language: An experimental study. Evol Psychol 11(4):147470491301100409. https://doi.org/10.1177/ 147470491301100409

Scott-Phillips T, Blancke S, Heintz C (2018) Four misunderstandings about cultural attraction. Evol Anthropol 27(4):162-173. https://doi.org/10.1002/evan.21716

Sénécat A (2017, 19 December) Facebook, voyage au cœur de la machine à fausses informations. Le Monde. https://www.lemonde.fr/les-decodeurs/article/2017/ 12/19/facebook-voyage-au-c-ur-de-la-machine-a-faussesinformations_5231640_4355770.html

Sénécat A (2018) Santé+ Magazine, un site emblématique de la « mal-information » sur la santé. Le Monde. https://www.lemonde.fr/les-decodeurs/article/2018/ 05/25/sante-magazine-un-site-emblematique-de-la-mal-information-sur-lasante_5304505_4355770.html

Sénécat A (2019) Critiqué pour ses intox, Santé + Magazine assure avoir changé. Vraiment? Le Monde. https://www.lemonde.fr/les-decodeurs/article/2019/07/ 17/epingle-pour-ses-intox-sante-magazine-assure-avoir-changevraiment 5490398 4355770.htm

Silverman C (2016) This analysis shows how viral fake election news stories outperformed real news on Facebook. BuzzFeed. www.buzzfeednews.com/article/craigsilverman/ viral-fake-election-news-outperformed-real-news-on-facebook.

Sperber D (1996) La contagion des idées: théorie naturaliste de la culture. Odile Jacob, Paris, France

Stubbersfield JM, Dean LG, Sheikh S, Laland KN, Cross CP (2019) Social transmission favours the 'morally good'over the 'merely arousing'. Palgrave Commun 5(1):1-11. https://doi.org/10.1057/s41599-019-0269-y

Stubbersfield JM, Flynn EG, Tehrani JJ (2017) Cognitive evolution and the transmission of popular narratives: a literature review and application to urban legends. Evol Stud Imaginative Cult 1(1):121-136. https://doi.org/ $10.26613 /$ esic/1.1.20

Stubbersfield JM, Tehrani JJ, Flynn EG (2015) Serial killers, spiders and cybersex: social and survival information bias in the transmission of urban legends. $\mathrm{Br} \mathrm{J}$ Psychol 106(2):288-307. https://doi.org/10.1111/bjop.12073

Swire-Thompson B, Lazer D (2019) Public health and online misinformation: challenges and recommendations. Annu Rev Publ Health 41. https://doi.org/ 10.1146/annurev-publhealth-040119-094127
Tan AS, Lee CJ, Chae J (2015) Exposure to health (mis) information: lagged effects on young adults' health behaviors and potential pathways. J Commun 65 (4):674-698. https://doi.org/10.1111/jcom.12163

Tapper J (2016) Fake news stories thriving on social media. CNN. https://www.cnn. com/videos/politics/2016/11/17/fake-news-social-media-tapper-dnt-lead.cnn

van Leeuwen F, Parren N, Miton H, Boyer P (2018) Individual choose-to-transmit decisions reveal little preference for transmitting negative or high-arousal content. J Cog Cult 18(1-2):124-153. https://doi.org/10.1163/1568537312340018

Verelst F, Willem L, Beutels P (2016) Behavioural change models for infectious disease transmission: a systematic review (2010-2015). J R Soc Interface 13 (125):20160820. https://doi.org/10.1098/rsif.2016.0820

Vosoughi S, Roy D, Aral S (2018) The spread of true and false news online. Science 359(6380):1146-1151. https://doi.org/10.1126/science.aap9559

Wang Y, McKee M, Torbica A, Stuckler D (2019) Systematic literature review on the spread of health-related misinformation on social media. Soc Sci Med 112552. https://doi.org/10.1016/j.socscimed.2019.112552

Wardle C, Derakhshan H (2017) Information disorder: toward an interdisciplinary framework for research and policy making. Council of Europe Report 27

Wirtz JG, Sparks JV, Zimbres TM (2018) The effect of exposure to sexual appeals in advertisements on memory, attitude, and purchase intention: a metaanalytic review. Int J Adv 37(2):168-198. https://doi.org/10.1080/ 02650487.2017 .1334996

\section{Acknowledgements}

We would like to thank Hugo Mercier for his extensive feedback and numerous corrections on previous versions of the manuscript. We are really grateful to Dominique Cardon and Chantal Lacourarie for proofreading our manuscript and for their precious feedbacks and corrections. We thank Guillaume Plique, Audrey Baneyx, Benjamin Ooghe-Tabanou and Jean-Philippe Cointet who helped us a lot with the management of our data, as well as Sylvain Parasie who gave us very useful recommendations. We are also thankful to Camille Williams, Pleen Lejeune and Anne-Sophie Hacquin for taking the time to code our sample. Edgar Dubourg also provided valuable assistance.

\section{Competing interests}

The authors declare no competing interests.

\section{Additional information}

Supplementary information is available for this paper at https://doi.org/10.1057/s41599 020-0452-1.

Correspondence and requests for materials should be addressed to S.A.

Reprints and permission information is available at http://www.nature.com/reprints

Publisher's note Springer Nature remains neutral with regard to jurisdictional claims in published maps and institutional affiliations.

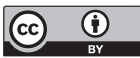

Open Access This article is licensed under a Creative Commons Attribution 4.0 International License, which permits use, sharing, adaptation, distribution and reproduction in any medium or format, as long as you give appropriate credit to the original author(s) and the source, provide a link to the Creative Commons license, and indicate if changes were made. The images or other third party material in this article are included in the article's Creative Commons license, unles indicated otherwise in a credit line to the material. If material is not included in the article's Creative Commons license and your intended use is not permitted by statutory regulation or exceeds the permitted use, you will need to obtain permission directly from the copyright holder. To view a copy of this license, visit http://creativecommons.org/ licenses/by/4.0/.

(c) The Author(s) 2020 